\title{
Uncertain pasts and risk-sensitive futures in sub-Saharan urban transformation
}

\author{
Mark Pelling, Alejandro Barcena, Hayley Leck, \\ Ibidun Adelekan, David Dodman, Hamadou Issaka, \\ Cassidy Johnson, Mtafu Manda, Blessing Mberu, \\ Ezebunwa Nwokocha, Emmanuel Osuteye and \\ Soumana Boubacar
}

\section{Introduction}

The Sustainable Development Goals (SDGs) challenge urban planners, risk professionals, researchers and citizens to extend their focus from accounting for the status of risk towards understanding and acting on the processes that can enable a transition to more risk-sensitive and transformative urban development across all contexts. Risk-sensitive development is required to reduce risk that has accumulated in the city and to better consider risk when planning new developments (Jones and Preston, 2011). This includes building design, construction and land-use planning, enhanced infrastructure access and maintenance, risk awareness and planning for emergency response and reconstruction, including social safety nets and insurance. To deliver a sustainable city for all requires a more frank and comprehensive focus on procedure: Who makes decisions, under which frameworks, based upon what kind of data, and with what degree and direction of accountability?

This chapter explores the status and the scope for transition of risksensitive and transformative urban development in diverse cities of sub-Saharan Africa. Sub-Saharan Africa is important because of its large proportions of urban populations with high vulnerability and growing exposure to risks (Fraser et al., 2017). High rates of urban growth pose increasing risks as we go into the future, yet there is also opportunity to reduce risk through integrating risk management into development 
(Satterthwaite and Bartlett, 2017). However, this opportunity space is often constrained by limited capacities to plan and manage the rapid urbanisation process, particularly in informal settlements. Limited capacities to prevent processes of risk accumulation pose threats to poverty reduction and sustainable development (Dodman et al., 2017). In this context, there is an increasingly urgent need for squarely recognising and addressing the underlying vulnerabilities of urban populations and their root causes. Transitioning towards such sustainable urban pathways will require the strengthening of capacities and accountability of city authorities and broader governance systems, both formal and informal (Pelling et al., 2018).

Complex relationships between risk (likelihood of future loss and damage) and vulnerability (propensity or predisposition to be adversely affected) and other elements of development and human well-being require detailed analysis and advanced understandings (Thomalla et al., 2018). This connects to the SDGs, which integrate risk management throughout, specifically in Goal 1: Eradicating Poverty, and Goal 11: Sustainable Cities and Communities. Particularly important for the SDGs is understanding and addressing the full spectrum of risk, encompassing everyday risks (e.g. environmental/public health risk; man-made hazards such as poor solid waste management), small and large events, their interlinkages and relative changes in their nature, scale and distribution (Fraser et al., 2017).

This chapter draws from a large multi-disciplinary, multi-country programme of research and capacity building - Urban Africa: Risk, Knowledge (Urban ARK) - focused on understanding risk in sub-Saharan Africa. The programme works in nine cities across eight countries and aims to address gaps in data, understandings and the capacity to break cycles of risk accumulation. This is pursued through a partnership between researchers, practitioners and city- and community-level activists. The experience and analysis of four cities in particular are considered here: Karonga, a small town in northern Malawi; Ibadan, a regional centre in Nigeria; Niamey, capital city of Niger; and Nairobi, capital city of Kenya and a regional core city. These four cities are chosen for their regional coverage across sub-Saharan Africa, the range of sizes, risk vulnerability profiles and breadth of illustrative blockages and opportunities for risksensitive development.

The second section presents a common analytical framework to help identify blockages and opportunities for a transition towards a risk-sensitive and transformative urban development. This framework was initially 
proposed in Pelling et al. (2018) and is further developed and applied here through detailed investigations of blockages and opportunities to transition based on synthesised empirical research undertaken in the four key cities under the Urban ARK programme since 2015. The framework is illustrated through each city in turn: Karonga, Ibadan, Niamey and Nairobi. A concluding discussion reflects on city observations to draw out recommendations for city-level and wider action and research partnerships.

\section{Blockages and opportunities for transition towards a risk-sensitive and transformative urban development}

Risk management continues to be a policy archipelago, distanced from the mainstream of development activity and strategy. How can research work in partnership with practitioners and stakeholders at risk to support a transition towards a more integrated vision, process and practice of risk management? Figure 3.1 identifies three key blockages to this transition and three opportunities drawing from recent research under the Urban ARK programme in sub-Saharan Africa (Pelling et al., 2018). The figure shows that transition is constrained by fragmented governance, donor priorities and inadequate monitoring of hazards, impacts and vulnerability.

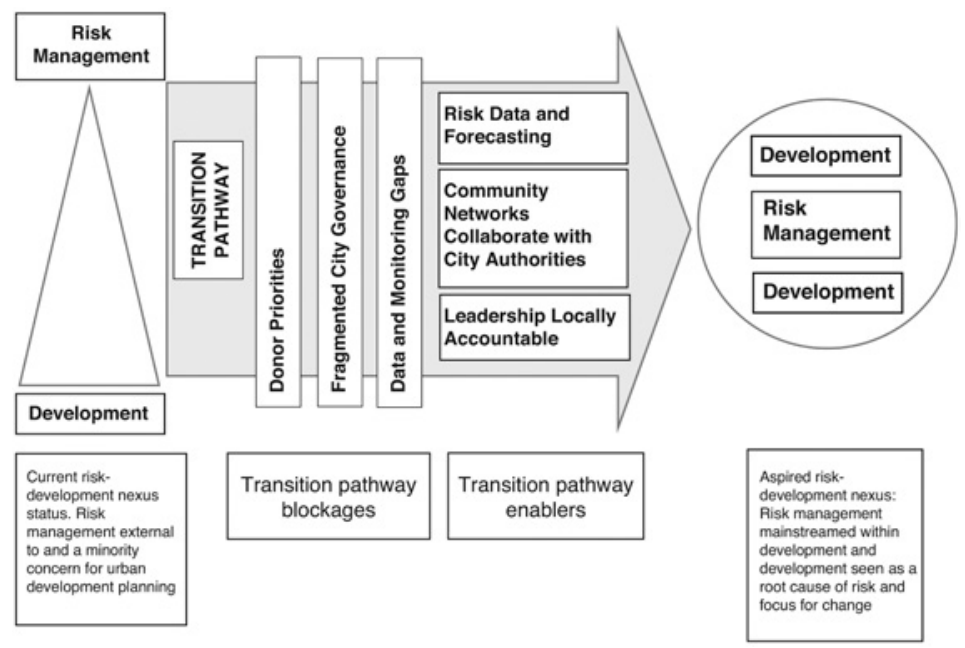

Figure 3.1 Blockages and opportunities for urban risk transitions 
While there is no formal agreed-upon definition, transformative urban development implies a radical change to systems and shifts to new modes of urban planning, management and governance, thereby leading to new development pathways (Revi et al., 2014; Roberts and O'Donoghue, 2013). Building on this, Revi et al. (2014: 13) propose that effective city-based disaster risk management and risk reduction provide a strong foundation for transformative urban development and adaptation, which also necessarily entails 'effective multi-level urban risk governance, alignment of policies and incentives, strengthened local government and community adaptation capacity, synergies with the private sector and appropriate financing and institutional development'.

These issues are explored here through the application of our conceptual framework presented in Figure 3.1. It investigates key constraints to achieving this in practice but also highlights important opportunities where pockets of transformative urban development are beginning to emerge in practice. Institutional gaps relating to weak capacities, inadequate resources, lack of systematic coordination and divisions between formal and informal systems are a priority blockage to data collection mechanisms and hazard-monitoring capabilities in urban sub-Saharan Africa. The frequent absence of systematic loss records, geo-referenced and gender disaggregated, constrains the possibility of correlating development drivers with risk.

Effective practices and policies in urban planning and governance in reducing risk are considerably less well documented than the reasons for ineffective planning systems and local governments in postcolonial African cities (Adelekan et al., 2015). This chapter responds to Adelekan et al.s call to fill this lacuna through highlighting examples of effective partnerships between city governments, local populations and civil society organisations (e.g. Nairobi Mukuru SPA, documented later) that address gaps in the risk-development nexus. Ajibade et al. (2016) asked, 'who are the dominant actors that can trigger a transition?' and whether transition windows (e.g. political and institutional change) can be utilised to enhance equity and future risk reduction.

In this chapter, we show how opportunities for transition arise through several channels, notably when organised civil society collaborates with the city government and other actors (Pelling et al., 2018). Citizen-led approaches for risk-related data collection have been shown to be critical for advancing early warning of hazard (Fraser et al., 2017; Pelling et al., 2018). Political and institutional change can trigger processes of transition 
and transformation (Kemp et al., 2007; Pelling, 2010). Transitions theory strongly recognises that innovations in multi-level governance can offer the potential for transition (Ajibade et al., 2016). There is also major opportunity for transition through the actions of networked civil society in many sub-Saharan African cities (Makau et al., 2012) that are driving demand-led and inclusive planning for risk (see below for the Nairobi case). There is further scope for transition if development donors partner with and provide finance opportunities to such independent actors at scale.

However, the interplay between actors and decision-making processes are continuously negotiated through unequal power relations and situated within broader political economic forces, which can disrupt transitions (Ajibade et al., 2016; Solecki et al., 2017). In cases where multi-level governance remains fragmented, top-down agendas often shape cities' decisions - with inadequate attention to local risk and development priorities. Fundamental shifts in institutional thinking are also required, from predominant disaster-focused, short-term views to longer-term perspectives that emphasise vulnerability reduction, addressing root causes and equity considerations (Conway and Schipper, 2011; Ziervogel et al., 2017). However, as Conway and Schipper's Ethiopian-based study shows, this is challenging to achieve, 'precisely because many institutions have been specifically set up to respond to emergencies, including food aid, whose raison dêtre is put into question by a new approach' (Conway and Schipper, 2011: 235).

Using the above framework as a critical lens, the chapter now considers blockages and opportunities for transition towards risk-sensitive and transformative urban development through the four case study cities Karonga, Ibadan, Nairobi and Niamey. Dodman et al. (2019) provide a detailed overview of the range of methods used across the programme for understanding the spectrum of risks in each study city. Here we have synthesised findings from studies in each city where multiple data types and results from a range of methods are used. These include documentary and institutional analysis, community data and participatory approaches (e.g. community-led risk assessment and resource mapping), as well as surveys and interviews for the four city cases. The city cases introduced above are based on the following core questions, guided by the theoretical framing in Figure 3.1: How is risk currently managed by the city? What are the donor priorities, city governance structures, and data and monitoring gaps? What are the barriers to transition and pathways to transition, 
particularly related to risk data and forecasting, community networks in collaboration with city authorities, and locally accountable leadership?

\section{Transition in the risk-development nexus: city cases}

Guided by the theoretical framing summarised in Figure 3.1, the next sections explore these findings in detail with illustrative examples for each city in turn.

\section{Karonga, Malawi}

The small but rapidly growing urban centre of Karonga (Karonga Town) is in the north of Malawi. Karonga's population is projected to increase from 41,000 inhabitants in 2008 to approximately 63,000 in 2018 (Wanda et al., 2017). The town is vulnerable to multiple small and large disaster risks and has been affected by earthquakes, drought and floods (Manda, 2014; Wanda et al., 2017). Everyday risks such as poor-quality and inadequate sanitation and unsafe water also pose significant threats for inhabitants (Holm et al., 2018). However, the nature and scale of risks in Karonga remains poorly understood (Manda and Wanda, 2017). This is partly attributable to the lack of political attention to small towns throughout Malawi (Wanda et al., 2017).

Disaster risk governance in Karonga Town faces considerable challenges. Firstly, the town's rapid growth has led to an increasing demand for services and risk-reducing infrastructure, yet provision is constrained by limited capacities and funding within local government (Holm et al., 2018). As with other urban centres in Malawi and across sub-Saharan Africa, growth in Karonga is largely informal (Manda, 2014). Secondly, the town council was dissolved in 2009, resulting in the town being governed by the Karonga District Council, a rural local government. The Karonga District Council is significantly over-stretched in governing urban development challenges. This weak governance structure has resulted in poor planning and project implementation, and consequently the accumulation of risk. A further major constraint to disaster risk governance is that there are no locally held systematic records on urban disasters and losses for Karonga Town. The district-level data mainly covers large intensive disaster episodes (e.g. earthquakes and large-scale floods). Moreover, when disaster records are in place, they are often inadequately taken into account. For example, while Karonga Town registered the largest number of disasters in Malawi between 1946 and 2008 in district and other available data sets, this has 
not been well recognised in planning or policy (Lunduka et al., 2010). More systematic disaggregated data at the sub-district level (especially from extensive and everyday risks) is necessary for effective policy formulation and planning.

Malawi published its Disaster Risk Management (DRM) policy following significant pressure from development partners and donors. Though national and international partners committed to assist the country's response strategy during the extensive floods of 2015, their support was conditional upon a conducive policy framework being in place. This situation exemplifies the nature of policy and practice of urban planning in Malawi and indeed many cities in sub-Saharan Africa, which are largely influenced by external agents. The policy has notable weaknesses limiting its effectiveness. Significantly, Malawi's urban areas are not specifically addressed, despite the increasing trend of urban disasters, and resource allocation to lower governance levels is highly inadequate (Manda and Wanda, 2017). Donors' priorities play a significant role in shaping DRM agendas at all scales. The Malawi government has received major loans from multiple international agencies (e.g. the African Development Bank and the World Bank) which have mainstreamed disaster risk consideration in development initiatives. Yet, these loans have created large-scale debts. The implementation of policy in Karonga Town tends to be externally driven. The national government acts both to direct policy and to support implementation. Policy implementation often focuses on disaster response. Very little attempt is made proactively to reduce risks either through capacity building or infrastructure upgrading.

The accountability ladder is fragmented, occurring separately between state actors on the one hand and community groups and their traditional leaders on the other. City officials are mandated to report to national policymakers. Accountability at the city level is expected through the ward councillors, but there are no such wards in place in the case of Karonga Town (Manda, 2014). Instead, ward councillors report to the citizens through traditional leaders. NGOs who have presence in the community play a bridging role and participate in the local government meetings through the District Executive Committees (DEC). Sometimes, the DEC meetings are funded by the NGOs: the prominent influence of the latter risks the independence of the DECs. The 2015 DRM policy provides for interaction between communities and councils through a decentralised reporting mechanism - the lowest level is the village DRM committee, followed by the area DRM, the district DRM committee and 
the National Platform at the highest level. In practice, the reporting chain is not always fully established and the committees do not always have a specific urban focus.

Recognising this gap, Urban ARK researchers from Mzuzu University sought to facilitate collaboration between the local government and the community. This was achieved through the establishment of a DRM committee in one of the neighbourhoods of Mzuzu, a small urban centre in northern Malawi. The committee is a significant platform for information sharing between researchers, local government representatives and community members. Furthermore, Mzuzu University and the Sierra Leone Urban Research Centre established local Community Hubs under Urban ARK in Karonga, Malawi and Freetown, Sierra Leone. The hubs are centres for learning and coordinating community programmes resulting from participatory risk assessments in the two urban centres.

Despite these opportunities, mainstreaming disaster risk reduction (DRR) for various hazards and a transition towards risk-sensitive development remains a significant challenge in Karonga due to multiple interacting factors, including the absence of a functional urban local government, inadequate financing, inherent failures to plan and regulate growth and silo-based approaches (Manda and Wanda, 2017).

\section{Ibadan, Nigeria}

The city of Ibadan, the capital of Oyo State in Nigeria, is the largest traditional urban centre in sub-Saharan Africa. It has one of the highest population densities in the country, with a considerable annual population growth (Adelekan, 2019) that is concentrated largely in informal areas. The city is exposed to a range of disaster risks including windstorms, flooding, fires, communicable and infectious diseases, road accidents and violent crime (Adelekan, 2019).

The management of risk in Ibadan is guided by the 2010 National Disaster Management Framework and the 2017 National Policy on Disaster Risk Reduction. The policy recommends a government-led approach, including multi-agency and development partners. While emphasis is given to proactive and multi-scalar risk governance, implementation remains fragmented (Ziervogel et al., 2017). Several government bodies are involved in the management of everyday and disaster risks in Ibadan, with varying degrees of success depending on resources and institutional capacity (e.g. the Bureau of Physical Planning and Development Control, the Ministry of Health, Environment and Water Resources, Nigeria Security 
and Civil Defence Corps, and the Department of Fire Service). Significantly, international donors have funded the Ministry of Health in the implementation of programmes addressing public health risks (e.g., malaria, tuberculosis); however, systematic mainstreaming of DRR is missing. Limited coordination and overlapping responsibilities among various government ministries and agencies in risk management constrain their collective potential.

In practice, institutional attention remains focused on reactive and centralised efforts. Whereas the Oyo State Emergency Management Agency is mandated by law to address risk management in Ibadan (i.e. preparedness, mitigation, response and recovery), the agency has largely focused on emergency response, during small and large disaster events, including floods (Oyo State Law, 2008). The same law requires eleven Local Government Areas in Ibadan to establish Local Emergency Management Committees, but Olaniyan et al. (2018) found poor compliance due to inadequate funding, weak local government and an unstable political system.

Internal and external donors shape risk management priorities due to weaknesses in public financing, knowledge gaps and the low capacity of government staff. Local governments still depend on the federal and state governments for funding. For the most part, funding decisions are influenced by complex political motives, including the political affiliations of local populations and the loyalty of local government administrators to higher-level government functionaries. A significant example can be drawn from the 2011 floods in Ibadan, when the state government requested a credit facility to address infrastructural challenges related to the floods. However, the Global Facility for Disaster Reduction and Recovery recommended the Ibadan Urban Flood Management Project (IUFMP), which was shaped by Pillar Two of the World Bank's Africa Strategy, and the World Bank/Nigeria Country Partnership Strategy (2014-17). Furthermore, the state government identified forty-eight river canals for dredging and widening, of which only thirty-six were approved by the World Bank. Forty communities, not benefiting from this programme, continue to ask the government for assistance in this regard.

Risk data collection remains poor in Ibadan, as in other Nigerian cities. City data (i.e. socio-economic), where available, is mainly provided at the level of local government associations. The lack of census data at lower levels (i.e. wards and localities) remains a significant challenge for city risk assessment. The inventory of risk-related events is poor, incomplete and generally inaccurate, mainly limited to events with significant impacts. 
Lack of city-wide risk data covering the whole spectrum of risks is a key limitation to informed risk-related decisions, including development planning. The Urban ARK Ibadan city programme has contributed to narrowing this gap by collecting city-wide data on everyday risks, as well as small and large disasters, disaggregated at ward level and using methods such as DesInventar, household/community assessments and consultations of city officials, household surveys and focus group discussions with community members. This information has the potential to inform the decision-making of city authorities.

Community organisations have shown a potential for risk-sensitive transitions in Ibadan. For instance, Community Development Associations (CDAs) are involved in risk-reduction activities (e.g. infrastructural development, maintenance of roads, water supply, and flood and erosion control) and community members played a significant role in the monitoring and enforcement of risk-related guidelines (e.g. waste disposal and construction areas). They are also increasingly engaged in risk-reduction decision-making, although their influence remains limited. For example, traditional leaders, CDAs and community organisations are engaged in risk-reduction meetings such as those of the IUFMP. Urban ARK's Ibadan programme has established a forum of exchange between community leaders, trade associations, city officials, NGOs, civil society groups and researchers. These spaces have allowed the identification of stresses and everyday hazards and the development of a city risk-reduction plan. This is a considerable opportunity for a transition in the risk-development nexus in Ibadan, but it will require ongoing advocacy and support.

\section{Nairobi, Kenya}

Nairobi is a large and rapidly growing city: the second largest in East Africa, with considerable regional economic and political significance. The majority of Nairobi's over 3.3 million population live in informal/ unplanned areas, low-lying and flood-prone, with very limited basic services and infrastructure. Poverty, food insecurity and other environmental vulnerabilities are widespread. These challenges are compounded by multiple interacting shocks such as disease outbreaks. Nairobi's social and political environments are characterised by vast inequalities (Myers, 2016). Rapid and unplanned urbanisation has led to increased flood risk. Weak governance and consequent poor service delivery have exacerbated man-made hazards such as poor solid waste management, with significant negative health impacts (APHRC, 2017). This is typified by the Dandora 
municipal open dumpsite, located close to public institutions, posing a range of health risks to an estimated 250,000 people (Kimani, 2007).

Climate risks and vulnerabilities are increasingly well recognised in the city, with several recent developments such as the Rockefeller 100 Resilient City status providing some impetus. There is increasing willingness for change among key city actors (i.e. risk managers and urban planners) (Pelling et al., 2018). However, as with many other sub-Saharan African contexts, risk management remains constrained by weak coordination between sectors and scales of governance, and complex policy landscapes where implementation is widely lacking. There is also a need to better understand interactions and cascading effects between different hazards and their potential effect.

The tensions between formal and informal planning systems and governance arrangements also require urgent attention. Disaster risk management in Nairobi is highly complex, with a lack of clarity in roles and responsibilities within the devolved governance structure. The devolved system of governance in Kenya came into effect in 2010 when the new Constitution of Kenya (ROK, 2010) was adopted. Under the constitution there are two overarching levels of governance - national and county government. Nairobi City County is further devolved into sub-county, ward and village levels. Within this formal structure, the chieftaincy plays a key role (albeit informally and contested in many cases) in linking communities with the lowest level of government, particularly in informal settlements which are often divided according to tribal affiliation (Mitra et al., 2017). The devolved system of governance has proved complex with ongoing challenges, fragmentation and conflicts across all governance scales. The constitution recognises disaster risk management as a developmental challenge that should be addressed at both county and national government levels, as well as local levels (ROK, 2010). A National Policy for Disaster Management (ROK, 2009) was formulated in 2009 with the intention of clearly identifying institutional mechanisms and responsibilities for DRR and unifying existing ad hoc policies relating to DRM in the country. However, more than a decade later, this is still awaiting cabinet approval and thus coordination challenges remain across all levels.

Transition pathways are evidenced in emergent innovative and inclusive approaches to governance, such as collective actions of networked civil society, often in collaboration with local government and other actors. For example, the Kenyan slum-dweller federation Muungano wa Wanavijiji led the advocacy campaign, with technical assistance from the Akiba 
Mashinani Trust and Slum Dwellers International-Kenya (SDI-K), which concluded with the designation of the Mukuru informal settlement as a Special Planning Area (SPA). The Nairobi City County designated the SPA in August 2017. Interdisciplinary consortia including academic, government, private sector and civil society actors have synthesised data and generated policy briefs to inform risk-sensitive planning strategies. Muungano has adopted innovative approaches to mobilise residents and collect data, which have benefited from Urban ARK support. While the initiative is still in its early stages, this is a notable transition in state-civil society relations in Nairobi and could serve as a catalyst for governance reform in other urban centres across sub-Saharan Africa. Based on their research on slum upgrading in Kibera, Nairobi for Urban ARK, Mitra et al. (2017) explain that such integrative approaches can become important tools for strengthening resilience to risks such as flooding, conflict and security through building trust between communities, government and other actors.

Disaster risk governance in Nairobi is constrained by inadequate systematic data on everyday and large-scale disasters. However, findings from Urban ARK research in Nairobi and other sub-Saharan African cities have highlighted the potential of drawing on detailed risk data collected by civil society organisations to identify and act on disaster risk (Allen et al., 2017a and 2017b; Satterthwaite and Bartlett, 2017). For example, SDI have prepared detailed profiles and maps of informal settlements in Nairobi and use this information to support state engagement. This has been a major factor in supporting the development of the SPA. There is further opportunity for addressing the disaster risk data challenge through drawing on long-standing local data collection initiatives on risks, broader urbanisation processes and urban health and well-being statistics, especially for informal settlements in the city (Satterthwaite et al., 2019). These initiatives have been led by local, national and international research institutes such as the African Population and Health Research Center (APHRC) through the Nairobi Urban Health and Demographic Surveillance System from 2002 to date and the Nairobi cross-sectional slum surveys of 2000 and 2012.

In further recognition of the need to address fragmentation in DRM there have been recent calls from city actors, particularly the Nairobi City County, to develop a shared platform for information sharing and collaboration. Significantly, the Nairobi Urban Risk Partnership was proposed at an exploratory meeting initiated and facilitated by Urban ARK at the 
APHRC on 10 May 2017. The partnership brings together stakeholders leading various urban risk efforts in the city and aims ultimately to inform the development of an urban risk management plan, pursuant to the 2015 Nairobi City County Disaster and Emergency Management Act. The partnership is a useful central coordination body and information source for external funders and donors undertaking research and development interventions in the city. Overall, the partnership holds considerable potential for strengthening DRR and DRM in the city and improving coordination; however, sustained momentum is constrained by local government transition, competing political priorities and budget limitations.

\section{Niamey, Niger}

Niamey is the state capital of Niger and has grown from 30,000 inhabitants in 1960 to over 1 million in 2012 (Issaka, 2015). It is one of the poorest cities in sub-Saharan Africa and is growing rapidly with immigration from drought-prone rural districts. The city is facing increasing risks, principally flooding, public health issues and disease, and food insecurity (Boubacar et al., 2017). These risks are exacerbated by widespread economic precariousness, increasing unemployment, delinquency and conflict in neighbouring countries.

Poor land-use planning and limited infrastructure, combined with mounting population pressure, have resulted in the increased occupation of flood-prone areas (Boubacar et al., 2017). The State of Niger has adopted a housing policy and sanctions to regulate development in an attempt to provide improved and adequate housing and to prohibit construction in risky areas (e.g. Law 2017-20 of 12 April 2017). The 1997 liberalisation of the land market, combined with a lack of control, has amplified informal practices in access to land and building construction. Informal settlements have proliferated throughout the city and consequently the risk landscape has been strongly exacerbated.

Although urban governance is shared between the state, local and regional authorities, traditional rulers, donors and NGOs, there is limited coordination between them. Since 2000, Niamey has experienced an ongoing political decentralisation process, yet the split of functions and responsibilities between local government, chiefs and central government remains unclear. The considerable government staff turnover has led to weak coordination and implementation of risk-related interventions. This fragmentation in governance results in a lack of accountability and monitoring of actions. Whereas the state is responsible for monitoring 
all risk and development programmes, it lacks the resources to fulfil this responsibility. For instance, the large-scale cadastral survey undertaken by the Agence Française de Développement, meant to help support development and disaster management, came to an abrupt halt due to the agency's sudden disbandment and thus had very little impact.

In most development programmes, Niger relies heavily on the support of donors whose priorities often do not fundamentally align with urban dwellers' concerns. For example, while roads and sanitation are the major problems in the city, donors' principal interventions have been to finance the cadastral survey and draw up an urban plan. Similarly, Niamey depends on external aid to respond to emergencies. The most relevant example is the World Bank-funded Niger Disaster Risk Management and Urban Development Project (World Bank, 2018), which includes the construction of flood-protection infrastructure and capacity building for urban development and disaster risk management. Furthermore, the National Food Crisis Prevention and Management System has been created with the coordination unit of the early warning system, funded by multiple donors. There is poor coordination between these different initiatives, but the recent creation of a ministry in charge of disasters and humanitarian action signals a possibility for future improvement.

In recent years there has been growing attention on urban risks in Niamey. For example, Urban ARK researchers from Abdou Moumouni University undertook an adapted household economy baseline study of vulnerability to flooding, as well as an inventory of small-scale disasters using DesInventar (Issoufou and Lecumberri, 2015). The Network on Hydrometeorological Risks in African cities (RHYVA) has also undertaken extensive studies on the causes of flooding in Niamey. Research centres such as the Agro-Hydrometeorological Centre, the African Centre for Applications of Meteorology for Development and the Niger Basin Authority have also carried out work on the risks, leading to the production of the very first river flood risk maps in the city of Niamey. Data on disaster risks exist, but there is reluctance among many institutions to consolidate and make it openly accessible. There is no standardised flood-loss database for Niamey, yet multiple studies indicate a dramatic increase in the frequency and intensity of floods observed over the last decade (Casse and Gosset, 2015; Issoufou and Lecumberri, 2015). The state has failed to ensure coordination and to support open access data.

At the neighbourhood level, communities are increasingly self-organising and engaging with local authorities to help address local development 
and risk-related challenges: for example, women's and young people's groups that are involved in addressing hygiene and sanitation issues. These activities are carried out under the patronage of the neighbourhood chiefs. However, they are often undertaken on an ad hoc basis, with limited influence at other levels. Greater collaboration between the state and local communities would help to support disaster risk reduction across the city (Sudmeier-Rieux et al., 2015). As Revi et al. (2014: 28) emphasise, it is critical to focus on and understand how linkages are established between local governments, community organisations, researchers and other urban actors in defining and then driving alternative forms of risk reduction.

Overall, risk reduction in Niamey is constrained by several key factors: donors' priorities do not align with local priorities; urban governance is highly fragmented with unclear and sometimes conflicting roles and responsibilities between actors; data sets relating to flooding and other risks are fragmented, incomplete and sometimes contradictory, with open access remaining a challenge; and monitoring and evaluation of risk-related interventions remain weak. These constraints notwithstanding, there is opportunity for movement towards transition and transformation in risk management and development through recent progressive policies and initiatives such as the creation of the Ministry for Disasters and Humanitarian Action and the Risk and Disaster Management Programme, as well as increasingly active self-organised community groups that are addressing key disaster issues at neighbourhood scales and lobbying the government.

\section{Concluding discussion}

The growing vulnerability of many African towns and cities to disasters has been increasingly recognised in recent years (Castán Broto, 2014; Pelling and Wisner, 2009). A significant proportion of current and future development will be concentrated in the towns and cities of sub-Saharan Africa. This offers vast potential but at the same time such development futures are intertwined with disaster risks (Fraser et al., 2017). This chapter has shown that risk management in the four case study cities are characterised by considerable gaps and blockages, yet there are also several significant emerging innovative initiatives for overcoming these barriers. These issues have been explored through the application of the conceptual framework presented in Figure 3.1. This research is an important contribution given 
the scale and rate of urbanisation and urban risk development worldwide, particularly in Africa. In consonance with the SDGs' call for integrative approaches to risk and development, this chapter has shown that efforts to address urban development and governance challenges can support risk reduction, as well as question underlying political and power relations between diverse urban actors.

Urban risk governance includes all institutions that affect risk, not only the formal administering and management of disaster risk (Fraser et al. 2017), which reflects the increasingly recognised principle of co-production. The research has shown that where the state does not have the ability to provide all the necessary services to citizens, partnerships with non-state actors have proven complementary in a way that enhances accountability and legitimacy (Allen et al., 2017b; Mitlin, 2008). This study has underscored that, for transition and transformation in risk management to be achieved, there is a need for clearer administrative procedures and inclusive governance. This will require a transition from fragmented governance to more joined-up governance between civil society groups, city government, local universities, research institutions and other urban actors. Indeed, as previously noted, transitions theory places emphasis on change being interconnected with innovation and shifting relationships between governance actors (Pelling et al., 2018; Roberts and O’Donoghue, 2013). While the case studies have revealed considerable fragmentation and a lack of coordination in urban risk governance landscapes, there is also clear evidence of increasingly joined-up and demand-led governance, as illustrated by the Nairobi Mukuru SPA example. Here, an innovative and collaborative governance transition is being driven by communities and stakeholders occupying informal settlements. This shows significant potential for a transition towards progressive multi-level risk governance through collective action.

There appears to be increasing willingness from civil society, NGOs and local government to collaborate over resilience building, disaster risk reduction efforts and the recognition of the limits of acting alone. As Fraser et al. (2017: 108) argue, 'holism and partnership are necessary to bring risk and development together in ways that address multiple everyday risks and the linkages across levels and scale that define urban risks for people. However, there is also some concern that risk accumulation could be exacerbated by the involvement of external actors, particularly where priorities are not aligned, as discussed in the cases of Karonga and Niamey regarding recent donor-funded interventions. Similarly, Revi et al. (2014) also caution that care is required from governments and potential funders 
in supporting alternative forms of risk reduction led by citizen movements as 'this very support can co-opt and destroy the alternative ethos, governance form and pro-poor adaptation movement' that is important for transformative development.

The examples presented here also illustrate the considerable potential for researchers to work in partnership with practitioners and stakeholders to support a transition towards more integrated risk management. For example, Urban ARK researchers supported the formation of the Nairobi Urban Risk Partnership, the formation of DRM committees in Mzuzu and the establishment of a city stakeholders' platform on risk reduction in Ibadan, with the aim of developing a city risk reduction action plan. Furthermore, gaps in data and monitoring capacities require urgent attention and there is considerable potential for community-collected and owned data to help narrow this gap (Dodman et al., 2018).

It is well recognised that the diversity of urban sub-Saharan African contexts calls for flexible and context-specific approaches to risk management (Issaka, 2015). However, through the lens of the transitions framework presented, this chapter has demonstrated several key common mechanisms, blockages and opportunities for acting on the processes that can enable a transition towards more risk-sensitive and transformative urban development. As illustrated in Figure 3.1, achieving the SDGs will require a transition in the risk-development nexus where risk management is mainstreamed with development, and development is seen as a root cause of risk and as a focus for change. It also requires that we focus squarely on the processes and procedures that can enable a transition towards more risk-sensitive and transformative urban development across all scales and contexts. Moving forward to achieve this will require more inclusive governance, strengthened networked collaboration, locally accountable leadership and improved risk data and monitoring.

\section{Acknowledgements}

This research was supported by the Urban Africa: Risk Knowledge (Urban ARK) programme, funded by the UK Economic and Social Research Council (ESRC) and Department for International Development Humanitarian Innovation and Evidence Programme under Grant No. ES/L008777/1.

\section{References}

Adelekan, I. (2019). 'Urban dynamics and vulnerability to everyday hazards and disasters in Ibadan, Nigeria. Environment and Urbanization, 29(2): 597-617. 
Adelekan, I., Johnson, C., Manda, M., Matyas, D., Mberu, B., Parnell, S., Pelling, M., Satterthwaite, D. and Vivekananda, J. (2015). 'Disaster risk and its reduction: An agenda for urban Africa' International Development Planning Review, 37(1): 33-43.

Ajibade, I., Pelling, M., Agboola, J. and Garschagen, M. (2016). 'Sustainability transitions: Exploring risk management and the future of adaptation in the megacity of Lagos'. Journal of Extreme Events, 3(3).

Allen, A., Koroma, B., Osuteye, E. and Rigon, A. (2017a). 'Urban risk in Freetown's informal settlements: Making the invisible visible'. Urban ARK Briefing No. 6.

Allen, A., Walnycki, A. and von Bertrab, E. (2017b). 'The co-production of water justice in Latin American cities'. In A. Allen, L. Griffin and L. Johnson (eds), Environmental justice and urban resilience in the global south, 175-93. New York: Springer Nature.

APHRC (African Population and Health Research Center) (2017). Solid waste management and risks to health in urban Africa - A study of Nairobi and Mombasa cities in Kenya. Nairobi: APHRC.

Boubacar, S., Pelling, M., Barcena, A. and Montandon, R. (2017). 'The erosive effects of small disasters on household absorptive capacity in Niamey: A nested HEA approach. Environment and Urbanization, 29(1): 33-50.

Casse, C. and Gosset, M. (2015). 'Analysis of hydrological changes and flood increase in Niamey based on the PERSIANN-CDR satellite rainfall estimate and hydrological simulations over the 1983-2013 period'. Proceedings of the International Association of Hydrological Sciences, 370: 117-23.

Castán Broto, V. (2014). 'Planning for climate change in the African city'. International Development Planning Review, 36(3): 257-64.

Conway, D. and Schipper, E.L.F. (2011). 'Adaptation to climate change in Africa: Challenges and opportunities identified from Ethiopia'. Global Environmental Change, 21(1): 227-37.

Dodman, D., Leck, H., Rusca, M. and Colenbrander, S. (2017). 'African urbanisation and urbanism: Implications for risk accumulation and reduction'. International Journal of Disaster Risk Reduction, 26: 7-15.

Dodman, D., Adelekan, I., Brown, D., Leck, H., Manda, M., Mberu, B., Pelling, M., Rusca, M., Satterthwaite, D. and Taylor, F. (2018). 'A spectrum of methods for a spectrum of risk: Generating evidence to understand and reduce urban risk in sub-Saharan Africa'. Area, 00: 1-9.

Dodman, D., Leck, H., Pelling, M., Adelekan, I., Brown, D., Manda, M., Mberu, B., Rusca, M., Satterthwaite, D. and Taylor, F. (2019). 'A spectrum of methods for a spectrum of risk: Generating evidence to understand and reduce urban risk in sub-Saharan Africa'. Area, 51: 586-94.

Fraser, A., Leck, H., Parnell, S. and Pelling, M. (2017). 'Africa's urban risk and resilience'. International Journal of Disaster Risk Reduction, 26: 1-6. 
Holm, R.H., Kamangira, A., Tembo, M., Kasulo, V., Kandaya, H., van Enk, P.G. and Velzeboer, A. (2018). 'Sanitation service delivery in smaller urban areas (Mzuzu and Karonga, Malawi)'. Environment and Urbanization, 30(2): 597-612.

Issaka, H. (2015). 'Exode rural, urbanisation et sécurité privée à Niamey'. Les Cahiers d'Outre Mer, 2: 225-42.

Issoufou, O.H. and Lecumberri, N. (2015). 'Urban profile: Flood risk areas and other risks in the city of Niamey (Niger)'. Urban ARK Working Paper No. 3.

Jones, R.N. and Preston, B.L. (2011). 'Adaptation and risk management'. Wiley Interdisciplinary Reviews: Climate Change, 2(2): 296-308.

Kemp, R., Loorbach, D. and Rotmans, J. (2007). 'Transition management as a model for managing processes of co-evolution towards sustainable development'. International Journal of Sustainable Development and World Ecology, 14(1): 78-91.

Kimani, N.G. (2007). Environmental pollution and impact to public health: Implication of the Dandora Municipal Dumping Site in Nairobi, Kenya. Nairobi: Kutoka Network.

Lunduka, R.W., Phiri, M.A.R., Kambani, C. and Boyer, C. (2010). Malawi disaster risk reduction and climate adaptation research. Lilongwe: Cordaid.

Makau, J., Dobson, S. and Samia, E. (2012). 'The five-city enumeration: The role of participatory enumerations in developing community capacity and partnerships with government in Uganda'. Environment and Urbanization, 24(1): 31-46.

Manda, M. (2014). 'Where there is no local government: Addressing disaster risk reduction in a small town in Malawi'. Environment and Urbanization, 26(2): 586-99.

Manda, M. and Wanda, E. (2017). 'Understanding the nature and scale of risks in Karonga, Malawi'. Environment and Urbanization, 29(1): 15-32.

Mitlin, D. (2008). 'With and beyond the state - Co-production as a route to political influence, power and transformation for grassroots organizations' Environment and Urbanization, 20(2): 339-60.

Mitra, S., Mulligan, J., Schilling, J., Harper, J., Vivekananda, J. and Krause, L. (2017). 'Developing risk or resilience? Effects of slum upgrading on the social contract and social cohesion in Kibera, Nairobi'. Environment and Urbanization, 29(1): 103-22.

Myers, G. (2016). Urban environments in Africa: A critical analysis of environmental politics. Bristol: Policy Press.

Olaniyan, F., Adelekan, I. and Nwokocha, E. (2018). 'The role of local governments in reducing disaster losses and vulnerabilities in Ibadan'. Urban Africa: Risk Knowledge Programme Working Paper 2018.

Oyo State of Nigeria (2008). State Law, 2008, Government Gazette, Vol. 34, No. 4 (Part A).

Pelling, M. (2010). Adaptation to climate change: From resilience to transformation. London: Routledge. 
Pelling, M. and Wisner, B. (2009). Disaster risk reduction: Cases from urban Africa. London: Earthscan.

Pelling, M., Leck, H., Pasquini, L., Ajibade, I., Osuteye, E., Parnell, S., Lwasa, S., Johnson, C., Fraser, A. and Barcena, A. (2018). 'Africa's urban adaptation transition under a $1.5^{\circ}$ climate. Current Opinion in Environmental Sustainability, 31: $10-15$.

Revi, A., Satterthwaite, D., Aragón-Durand, F., Corfee-Morlot, J., Kiunsi, R.B.R., Pelling, M., Roberts, D., Solecki, W., Gajjar, S.P. and Sverdlik, A. (2014). 'Towards transformative adaptation in cities: The IPCC's Fifth Assessment. Environment and Urbanization, 26(1): 11-28.

Roberts, D. and O'Donoghue, S. (2013). 'Urban environmental challenges and climate change action in Durban, South Africa'. Environment and Urbanization, 25(2): 299-319.

ROK (Republic of Kenya) (2009). National policy for disaster management in Kenya. Nairobi: Government of Kenya, Ministry of State for Special Programmes, Office of the President.

ROK (Republic of Kenya) (2010). Constitution of Kenya 2010. Nairobi: National Council for Law Reporting.

Satterthwaite, D. and Bartlett, S. (2017). 'Editorial: The full spectrum of risk in urban centres: Changing perceptions, changing priorities'. Environment and Urbanization, 29 (1): 3-14.

Satterthwaite, D., Sverdlik, A. and Brown, D. (2019). 'Revealing and responding to multiple health risks in informal settlements in sub-Saharan African cities'. Journal of Urban Health, 96(1): 112-22.

Solecki, W., Pelling, M. and Garschagen, M. (2017). 'Transitions between risk management regimes in cities. Ecology and Society, 22(2): 38.

Sudmeier-Rieux, K., Paleo, U.F., Garschagen, M., Estrella, M., Renaud, F.G. and Jaboyedoff, M. (2015). 'Opportunities, incentives and challenges to risk sensitive land use planning: Lessons from Nepal, Spain and Vietnam'. International Journal of Disaster Risk Reduction, 14: 205-24.

Thomalla, F., Boyland, M., Johnson, K., Ensor, J., Tuhkanen, H., Swartling, Å.G., Han, G., Forrester, J. and Wahl, D. (2018). 'Transforming development and disaster risk'. Sustainability, 10(5): 1458.

Wanda, E., Manda, M., Kamlomo, D., Kushe, J., Mphande, C., Kaunda, J. and Msiska, O. (2017). 'Governing WASH for disaster risk reduction in Karonga Town, Malawi'. International Journal of Disaster Risk Reduction, 26: 69-77.

World Bank (2018). 'Niger disaster risk management and urban development project'. Implementation status and results report, 9 April.

Ziervogel, G., Pelling, M., Cartwright, A., Chu, E., Deshpande, T., Harris, L., Hyams, K., Kaunda, J., Klaus, B., Michael, K., Pasquini, L., Pharoah, R., Rodina, L., Scott, D. and Zweig, P. (2017). 'Inserting rights and justice into urban resilience: A focus on everyday risk'. Environment and Urbanization, 29(1): 123-38. 